\title{
Digitalization in Africa: Interdisciplinary Perspectives on Technology, Development, and Justice
}

\author{
Laura Schelenz, Kerstin Schopp \\ International Centre for Ethics in the Science and Humanities (IZEW) \\ University of Tübingen, Germany
}

\begin{abstract}
Digitalization transforms our everyday life, our way of communication and information, as well as our relationship to other people. Especially in African countries, digitalization is still under development and poses on the one hand risks, challenges, and difficulties, on the other hand opportunities, chances, and, and perspectives for users, providers, and politics. High hopes for development lie on Information and Communication Technologies (ICT) and their potential benefits for the Global South. From the ethical point of view, questions of power relations, neo-colonialism, and (gender) equality have to be addressed and considered in the broad discussions. In this context, it is important to structure and systematize the complex discourse on digitalization. Therefore, the following contextual levels will be addressed in this paper: Realities of digitalization in Africa; information access and the (gender) digital divide; stakeholders, power relations, and politics; and ethical questions about digitalization in Africa. This paper summarizes the results and our own reflections, thoughts, and ethical considerations of the conference "Digitalization in Africa: Interdisciplinary perspectives on technology, development, and justice" which took place in Tübingen, Germany, in September 2018.
\end{abstract}

\section{Introduction}

The people in the Global North are usually not exposed to the latest developments in Africa, it seems that news in the North increasingly include stories of Africa's digitalization process: Africa as an untapped pool of digital talent, Africa leapfrogging development and closing the digital divide, Africa as a home to start-ups and international tech hubs. Transnational corporations like Alphabet (Google), Facebook, but also the German IT company SAP increasingly deliver their services to Africans. Governments in Africa (but also China), development organizations, political groups, and researchers in academia also dive into the landscape of digitalization efforts in Africa - to promote, implement, or understand what is happening in Africa with regard to digitalization.
With such traffic around the topic "Digitalization in Africa", it is current and relevant to take a closer look at the issue. This paper draws on interdisciplinary perspectives gathered at the international conference "Digitalization in Africa: Interdisciplinary Perspectives on Technology, Development, and Justice" on September 26 and 27, 2018, at the International Center for Ethics in the Sciences and Humanities, Tübingen, Germany. It will bring together the expertise of speakers and participants to provide a comprehensive overview of the current state of digitalization, important political and ethical issues arising from digitalization processes in Africa, and give an outlook on what needs to be considered in the future of Africa's digitalization. The paper includes important ethical aspects, which are generally marginalized in the discussion around digitalization and development in Africa. Yet such ethical perspectives are crucial to evaluating Africa's digitalization process in terms of justice for people, and provide concepts for an inclusive and harmonious development of the African and international information society going forward.

The first section of the paper provides an overview of the status quo of digitalization in Africa. Much have been done to advance digitalization with improved telecommunications, regulations, electricity, and the integration of ICT in the banking and health industries, education, entertainment, and politics. Major innovations introduced in various African countries include cloud computing, communication tools (such as Gmail, Dropbox, WhatsApp, Skype), electronic record systems, and pharmacy dispensing units, mobile banking, and laptops and tablets for schoolchildren [1]. Moreover, tech hubs are emerging across the continent with currently 50 percent of hubs located in the digital frontrunners South Africa, Kenya, Nigeria, Egypt, and Morocco. The rhetoric prevails that ICT are a catalyst for social and economic development and can even empower women and girls [1].

At the same time, a (gender) digital divide persists. The second section of the paper addresses the issue of asymmetric access to information and identifies barriers for equal participation in digital life. Going hand in hand with questions of "who has access" are questions of power relations. The third 
section focuses on the relationship between international and national stakeholders in Africa's digitalization. The role of national governments in shaping digitalization is key here. Civil society has pointed to government abuses citing internet shutdowns, high costs and lack of subsidy of internet access, and cooperation with authoritative foreign regimes. Human rights are at the heart of the debate, and internet rights seem out of reach when massive offline human rights violations prevail. This leads us to ethical questions about digitalization in Africa, which is the content of section four. Ethical concerns include the dangers of "digital colonialism," the violation of privacy, and the exclusion or neglect of marginalized populations and the environment. Virtue ethics is identified as a useful approach that can help answer questions of global justice and digitalization.

\section{The realities of digitalization in Africa}

In general, Africa lags behind in digitalization but is no stranger to technology [2]. African countries have demonstrated resilience and are catching up in the global effort to building a digital planet. Nigeria, Kenya, and South Africa are at the forefront of the digital evolution in Africa. In Kenya for instance, "eCitizen - Gateway to All Government Services"1 allows people to access national services (including national transport, immigration services, civil registration, and business registration), bringing government administration to the people [3].

Government service provision through information and communication technologies (ICT), i.e. e-government, is popular in many African countries. Also, in remote areas, telecommunications centers try to ensure the connection of citizens to national administrations [2].

Furthermore, in Kenya and across Africa, mobile money transfers (through M-Pesa, Airtel Money or T-Kash) have spurred the creation of new jobs, and mobile banking/finance has become the go-to example of leapfrogging development: while populations in the Global North went from storing cash at home to creating bank accounts to online banking and might start adopting mobile banking in the future, Kenyans directly went from cash to mobile banking. Moreover, e-commerce has seen massive demand and increase in Kenya (e.g. via Kilimall or MA Soko), and land title registration online has also gained popularity [3]. Internet shopping is gaining relevance throughout Africa and consumers enjoy online sites such as jumia7, OLX8 or Ahonya9 [4]. ICT is also vital to agriculture, as digital soil maps or mobile applications (e.g. M-Farm in Kenya) help improve cultivating, harvesting, and selling agricultural products [2].

There is also activity to digitalize the city and answer to urban challenges with ICT implementation
(GPS, cameras, free Wi-Fi on public transport). One example is Cape Town in South Africa, where the smart city program "MyCiTi"11 aims at achieving a greener and more equal environment and reducing socio-economic segregation, insecurity, unemployment, and other urban problems such as pollution and congestion [5]. ICT implementation in Africa has also spurred social mobilization. One example is the documentation of human rights violations during or after elections (cf. Ushahidi12/Uchaguzi in Kenya's 2013 election; [3]). Social media plays an important role in communication and information processes, especially with authoritarian governments controlling mainstream media [6]. Facebook and WhatsApp are the most popular social media services in Zimbabwe, South Africa and many other countries [6, 7]. "The digital face of Africa is mobile" [6]. In 2018, around 82 percent of the population in Africa had a mobile connection; at the same time, the rate of internet users (34 percent), social media users (15 percent), and active mobile social users (14 percent) was much lower [7]. While mobile phones are prevalent throughout the continent, bandwidth is scarce and costs for internet access constitute a significant percentage of a user's income. Many people still rely on subsidized content but subsidized data is often limited or not available in certain areas [6]. Infrastructure and affordability therefore remain important issues on the agenda of Africa's digitalization. Users protest the high costs under the hashtag \#datamustfall on Twitter.

The reality is also that most Africans have no access to the internet [4]. Often, basic needs such as shelter, food, health, and education trump interest in ICT adoption. While there are concerns about basic social and economic supplies, as well as concerns about human rights abuses, the focus on digitalization seems unreasonable to many [6]. Moreover, with illiteracy persisting among indigenous populations (such as the Yoruba people in West Africa), imported ICT systems cannot be used as intended and people slowly adopt and appropriate ICT [8]. Even if users understand the language and are able to read and write, they may lack other skills such as basic electronic data processing knowledge needed to independently use ICT; this is especially true for women and girls [9].

\section{Information access and the (gender) digital divide}

Digitalization puts front and center the value of information and the communication through ICT. Therefore, information access is an important point of discussion among academics and stakeholders in Africa's digitalization. Unfortunately, information access is often limited for African people due to the realities of digitalization in Africa (see above): ICT 
devices and services (data) are barely affordable, ICT infrastructure is weak, and basic human needs (shelter, food, health) are prioritized. As a result of these and other factors (such as power relations and politics, which we address later), there is a global digital divide. The term "digital divide" refers to inequality with regard to access to and use of ICT, in particular computers, mobile phones, and their networks [e.g. 10: 221-222]. The digital divide is particularly wide between countries in the Global North and countries in the Global South. For instance, Western Europe has an internet penetration rate of 90 percent, while African internet penetration rates vary from as low as 12 percent in Central Africa to 51 percent in Southern Africa [7].

Skills such as literacy are very important and can facilitate access to information. This refers not only to ICT literacy but also to the ability to read and write. Illiteracy and language barriers remain a major challenge for digitalization in Africa [8]. At the local level, people are working around this issue by appropriating ICT to suit their needs and preferences. SMS, online platforms (whether e-government or social media) rely on written words and are often designed in a foreign language. Indigenous people such as the mostly illiterate Yoruba in West Africa struggle with the use of ICT, being unable to even buy airtime (credit for the phone) or know their mobile phone numbers. The Yoruba people have thus developed strategies (such as using signs and specific symbols or voice message on Whatsapp) to benefit from ICT [8].

Similarly, ICT use in Africa depends on the most basic ICT skills. Small steps matter, whether it is learning to create a blog entry or exploring all functions of one's phone. This is especially true for women and girls. Improving the digital skills of women can contribute to reducing the cycle of poverty and prepare women for the future of work [9], as women and girls are disproportionately excluded from digitalization processes. This fact can be summarized under the term "gender digital divide".

The gender digital divide refers to inequalities with regard to ICT access and use between men and women. For African women, the gender digital divide is even more extreme. Social, economic, and political barriers hinder women's access to ICT. Women have lower ICT literacy rates, less ownership of devices, and therefore less access [6]. Patriarchal structures and cultural practices hinder access further. For instance, many men (and women, since there are structures of complicity in the discrimination of women) consider the internet to contain inappropriate content for women, barring wives and daughters from using the internet. Moreover, many men (and women) are concerned about women neglecting their household responsibilities, which are ascribed to women due to the prevalence of gender roles. Men (and women) argue that women should not invest time to learn ICT skills or engage with the internet but rather care for the children and family [6]. This discrimination based on gender roles often intersects with the socioeconomic situation of women, meaning that poor women are the family caretakers and producers of food [9].

A barrier to information access for women is also gendered violence online. Doxing (the collection of material of one person online and subsequent publication), stalking, bullying, and even revenge pornography (when an ex-partner publishes intimate material about a person) are frequently experienced by women and girls. Furthermore, female politicians, journalists or in general women in the public sphere are harassed more often than their male counterparts. Women frequently receive sexist comment [6]. Violence may also extend into the private sphere, with a husband controlling his wife's mobile phone due to fear of the woman flirting online. Fear of repercussion from the family then also constitutes a hindrance for women's information access [1]. Finally, women have been found to lack confidence when it comes to ICT use. The technology-is-notfor-me-syndrome is prevalent with women being less interested in ICT and leaving the subject to men [1].

Another crucial barrier to people's access to information and ICT is government shutdowns and the repressive policies of African governments associated with such shutdowns [6]. Especially civil society actors (such as journalists, bloggers, advocacy organizations, human rights activists) suffer from such shutdowns, but these so-called blackouts also impede the economy and healthcare provision. Increasingly, civil society actors seek legal remedy by bringing the matter of internet shutdowns to national courts, e.g. in Cameroon [6]. One example is the case currently pending in Cameroon. Two NGOs, AccessNow and InternetSansFrontiers, challenged a prolonged shutdown in several regions in 2017 for violating international human rights law.13 This brings us to the matter of politics and power relations.

\section{Stakeholders, power relations, and politics}

Various stakeholders are involved in the process of digitalizing Africa. They include national governments, inter-governmental bodies such as the African Internet Governance Forum14, as well as foreign governments (especially China); transnational corporations like Microsoft, Facebook, Alphabet (Google), Alibaba, Baidu, Tecno Mobile, or the German IT company SAP15, but also national companies like start-ups and tech hubs; civil society organizations, activists, journalists, and of course users. 
National governments are very active in ICT implementation and can be considered key drivers of digitalization on the African continent [6]. Digital services increased (including e-government) and the mobile economy has created new jobs. Yet, Africa's digitalization agenda remains vague in terms of goals and steps to be taken. The African Internet Governance Forum prioritizes the following issues with regard to digitalization: affordable internet, bridging the gender gap, promotion of local content, cybersecurity and user protection, broadband access, and internet rights [6]. The implementation of such a (necessarily) broad agenda depends on national governments and their respective priorities.

In Tunisia, for instance, the national digitalization strategy focuses mostly on economic development since the country experiences a severe economic crisis. As part of the national development agenda, the government is engaged in implementing technological infrastructure, passing legislation such as the Startup Act16 in 2018, e-business, egovernment, and public-private partnerships. The hope is to create a modern economy, among other things. However, while ICT penetration is high, there are strong regional differences, and questions remain with regard to the potential creation of new inequalities and the participation of citizens [11].

Transnational companies can play a crucial role in empowering local people. Since career perspectives are missing in many regions in Africa, talented young people increasingly leave the continent to pursue a career elsewhere (brain drain). Providing economic opportunities through ICT-based jobs (data analysis, programming, information processing) then is an investment in people and countries. One example is the German-Ghanaian firm GetINNOtized17, which trains and employs people in Accra, Ghana, benefitting German companies but also creating jobs in Ghana [12].

However, transnational business cooperation in ICT is not always empowering. One example is ewaste: old computers, tablets, phones, and other worn-out technologies are being exported from countries in the Global North to African countries. Africa has become a "dumping ground for old technology" [1]. Since the waste is often not recycled but rather burned, air pollution, environmental destruction, and cancer are the consequences for African people, animals, and the environment [2].

The example of e-waste leads us to the question of global power relations, and how unjust practices such as the dumping of Western waste in African countries are possible. Certainly, history and politics are crucial factors here. From a postcolonial perspective, the digitalization processes in Africa must be observed with much worry, as the dominance of foreign players and foreign technology - and therefore foreign values, perspectives, and ideas - in ICT implementation resemble colonial structures. Are we actually witnessing "digital colonialism" in Africa [1]?

By exporting their products to a vastly different cultural context, Western transnational corporations impose their values (which are embedded in the design of their technologies) on African people. On the one hand, technology production, promotion, and export are based on the modernization idea, i.e. the idea that progress through technology is vital to advance societies. Accordingly, values such as rationality, efficiency, and problem-solving that have repeatedly been at the core of modernization discourse, dominate Western ICT systems. On the other hand, Western interpretations of values such as privacy are exported through value-laden technology. Such conceptions of privacy may conflict with conceptions of privacy dominating African societies (individualism vs. community). Another concern is that the import of Western technology may lead to dependency, leaving people without the ability to act and think outside of technology [2].

Furthermore, the heavy investment of China in Africa's digitalization raises questions about autonomy and freedom of expression [1]. China is a big player in digitalization processes in Africa. Among the most used ICT systems in Africa are those produced by Huawei (China), Tecno Mobile (China), Motorola (USA), Infinix (Hong Kong), and Samsung (South Korea). The aforementioned companies have started catering to the needs of Africans (e.g. by creating longer-life batteries as power supplies are scarce in many African regions) and realized the potential of African markets [6]. This raises concerns among scholars and practitioners. China as an authoritarian regime has little restraint when it comes to aligning with authoritarian governments in Africa and providing technology for repressive practices [1]. There are several dangers for African users of ICT resulting from unequal power relations. Global digital power differentials lead to the use of discriminating algorithms, gender bias, deepening the digital divide, abuse of private data, vulnerability of one's private information being hacked, and surveillance [1].

However, unjust power relations cannot be blamed on foreign governments only. The role of African governments is key as well. Governments in Africa engage in abusive practices themselves, e.g. many countries try to obtain maximum control of information flow. In various countries, users have to register for national security reasons in order to activate SIM cards. This means that anonymous communication (which might be crucial for collective action and political opposition) is compromised [1]. In Tanzania, a law passed in 2018 requires bloggers and creators of content to register with the government and pay fees. With underprivileged people being de facto barred from 
creating online content, "the majority of conversation about and in Tanzania risks becoming an echo chamber for the upper class" [13]. In other states (e.g. Kenya), posting videos or other content requires licenses for national security reasons [6].

The introduction of ICT has changed communication in all world regions. In Africa, particularly, traditional media consumption (of government-controlled news) gave way to the creation of own content, citizen journalism and activism. Governments have realized this change and fear losing control and power [6]. In an attempt to control information flow and especially social media, governments use internet shutdowns. "The Internet Society defines internet shutdowns as an intentional disruption of internet or electronic communications, rendering them inaccessible or effectively unusable, for a specific population or within a location, often to exert control over the flow of information thus they are a form of online censorship" [6]. Internet shutdowns occur mostly around the time of elections (e.g. after elections in 2016/17 in Uganda, the Republic of the Congo, Chad, Gabon, Niger, and Gambia), or during protests. These shutdowns have massive economic impact, compromising the promise of economic prosperity through ICT [6].

The role and behavior of African governments is not only key in national development but also in international negotiations. One example is the discussion around e-commerce. Trade and shopping online has seen massive demand in Africa and worldwide. E-commerce is on the rise; African governments cannot and do not want to curtail this trend [4]. Yet, when it comes to international negotiations on e-commerce (e.g. at the World Trade Organization, WTO), African governments are weak in position and performance. The USA and China push for liberal policies, for the free flow of data and the storage of such data in foreign countries. This has potentially dangerous implications for users, e.g. with regard to privacy and data protection. Big tech companies like Alphabet (Google), Alibaba, Amazon, Facebook, and Apple demand binding WTO rules on e-commerce (which would reinforce their monopoly and curtail competition). Such binding rules contain risks for African countries, as African companies have not yet entered the stage in e-commerce. African governments must thus become active and claim their seat at the table, adopting a strong role in international negotiations on internet governance [4].

According to Zimbabwean activist Koliwe Majama, users should be the most important stakeholders in Africa's digitalization [6]. However, users lack awareness that they have rights online as the human rights situation offline in many African countries is at least precarious. Activists and journalists are persecuted in many African countries, limiting free speech and expression [6].
Nevertheless, civil society organizations campaign for affordable internet and put a "right to affordable internet" at the heart of their efforts for equal access to ICT. The African Declaration on Internet Rights and Freedoms 18 was created by African media and ICT organizations and stresses the importance of an open internet, which must be available and affordable for all people [6].

Members of civil society call on African governments to step up, as access to information and affordable internet largely depend on political will [6]. National governments in Africa do not take enough action to ensure equal access to ICT. For instance, governments have at their disposal socalled universal services funds. These funds were raised to provide mobile and internet services to marginalized populations [6]. When money allocated in the funds is not spent, however, remote locations remain underserved. When government inaction or lack of political will prevents social justice and equality, this raises questions of accountability.

\section{Ethical questions about digitalization in Africa}

The paper has so far presented the status quo of digitalization in Africa. While much has been done to advance digitalization, divides in access to ICT persist between the Global North and Global South, men and women, rural and urban areas, and the generations. Power relations are asymmetric and transnational corporations, foreign governments, and national repressive policies shape Africa's development with regard to ICT. Originally, there was much optimism that connecting different world regions would automatically lead to equality. Even though the internet was available only to elites at first, the idea was that, as time goes by, everyone could eventually enjoy the benefits of digital life. Moreover, the tale went on that ICT would have a democratizing effect similar to a Habermasian ideal speech situation; as long as everyone had the opportunity to voice their opinion, democracy would flourish [14].

Ethicists have long realized that this technological determinism does not hold true in light of U.S. domination of global digitalization processes and social structures of inequality being replicated in the digital sphere [14]. Several ethical concerns about digitalization in Africa have been voiced, including 1) digital colonialism through value-laden technology, 2) the violation of privacy and its implications for societies and individual identities, and 3 ) the exclusion of marginalized populations and neglect of the environment. This section touches on these issues but in fact raises new questions about equity and global justice, which should be on the agenda of ethicists in the future. These questions and discussions are also highly relevant for other fields 
of study as well as computer scientists and development workers. Interdisciplinary perspectives are vital to monitor and evaluate digitalization processes in Africa.

Philosophers of technology argue that technology is not neutral but has certain values embedded in it. These values reflect the norms and standards of the society where the technology was developed [15]. When, for instance, technology developed in the United States is introduced in African countries, American values and practices of communication are introduced in local African communities together with these technologies. In the African context, the implementation of foreign values (especially through technology as a symbol of modernization and progress) is particularly delicate, as it resembles the imposition of European norms during colonial times. While African countries have struggled to decolonize and end control by European countries, digitalization may now path the way to new forms of colonialism, i.e. digital colonialism [1, 17]. One example of "digital colonialism" is Facebook's application "Free Basics". Facebook cooperates with African or international network operators to provide access to selected internet content free of charge and across Africa. The App includes Facebook, BBC, some pages of Wikipedia, and other sites such as job portals or maternal health information. The App "Free Basics" has been criticized for providing only certain content and violating principles of net neutrality, displaying mostly Western content and ignoring popular national or local websites, prioritizing English over local languages, not responding to the needs of users, and collecting large amounts of data [16]. Yet, Facebook's Free Basics is not the only program with heavy influence in African countries. Foreign tech giants including Google (which announced the establishment of an Artificial Intelligence research center in Accra, Ghana, in 2018), Microsoft, as well as Chinese investments shape digitalization in Africa, raising questions of data ownership, inequality of access, autonomy, and trust [1].

Ethical challenges relate not only to the dangers of foreign values being imposed on African societies through "computer-mediated cultural imperialism" [17: 116]. Digitalization through value-laden technology is complicated by the fact that different cultures might have different interpretations of the same value. One example is privacy. Whereas in North America and Europe, privacy is usually understood in terms of individual privacy, African and Asian cultures see privacy as relating to the community, i.e. privacy of the family but not individual privacy is valued. Ethicists (and computer scientists/development agents) must therefore consider African philosophical ideas about privacy (e.g. by engaging with the philosophy of Ubuntu), and how they conflict with privacy concepts embedded in ICT. Intercultural information ethics deals with exactly such ethical questions, aiming at integrating diverse cultural perspectives [14].

Privacy is a central concept in information ethics and the ethics of digitalization. Privacy is valued because it is considered a prerequisite for freedom and democracy, autonomy, and because it protects individuals from unwanted influence and manipulation including "scrutiny, prejudice, coercion, and pressure to conform" [18: 134; 19]. In the information age, threats to privacy are broad and widespread. One example is identity theft. With the help of malware such as "Trojan horses, worms, and viruses," hackers access bank accounts, email programs and browser histories, or other passwordprotected ICT-based tools and steal private information [17: 44f]. Other threats to privacy include government surveillance or corporate data collection without informed consent, but also the forming of a culture of publicity, where being away from the mobile phone and being unavailable is not an option [17].

In the African context, the matter of privacy and data protection is particularly sensitive with human rights abuses remaining frequent in many countries. Democratization can help to solve these problems and projects such as the Ushahidi documentation of human rights violations in Kenya are required to raise awareness and hold violators accountable [2]. When the privacy of computer scientists developing such human rights projects and the privacy of citizen journalists providing information about abuses is at stake, openness and justice are at stake. Another concern in the African context is the lack of digital literacy, e.g. knowledge how to protect oneself from unwanted privacy intrusions. The African Centre of Excellence for Information Ethics has identified this shortcoming in Africa's digitalization process. The Centre has created a toolkit and holds regular workshops in diverse communities to raise awareness about possibilities and dangers of navigating the online environment.

Ethical concerns have also been expressed about the exclusion of marginalized populations and the neglect of damaging effects of digitalization on the environment. Majama and Wakunuma criticize the persistence of a gender digital divide and the exclusion of women from access to ICT $[6,1]$. Sègla criticizes the exclusion of illiterate and indigenous populations from access to ICT [8]. Language and the design of technology matter as they determine who can benefit from technological innovations. Heeks asserts that the perspectives of end users (particularly the poor) are not taken into account in the development of devices, apps, and ICT literacy programs [20]. Marginalized populations are thus precluded from benefits of digitalization precisely because they are precluded from participation in the development of technology. Similarly, perspectives 
of environmentalists are not taken into account when creating (and destroying) technology. Kelbessa argues that e-waste (especially the export of e-waste to African countries) has serious effects on marginalized populations and the environment [2]. Codes of ethics and responsibilities must be established and followed when developing and introducing new technologies. Sustainable Development should be at the core of technological innovation [2].

Ethicists have not only identified ethical concerns about digitalization in Africa but also ethical responses and solutions to challenges. One approach suited to address the dangers of digitalization is virtue ethics. This approach allows people to explore new possibilities of "being" and helps answer the question "how can we be the best person?" [14]. Ideas of virtue ethics can be traced back to ancient Greek philosophy (Socrates and Aristotle) but also found in Confucian and Buddhist thought [17]. Virtue ethics is about human beings developing their abilities to reason and make judgments for a good life, for realizing well-being and happiness. This "becoming an excellent human being" in terms of developing "capacities as human beings" is an ongoing process and involves life-long learning and improvement [17: 207]. Working to make the right decisions as a human being is linked to the development of moral autonomy and self-guidance [17]. These ethical concerns and approaches to solutions lead us to new questions for all fields of study engaging in and reflecting global digitalization: "What does an equal and fair global digital society look like? And how can we put that into practice?" [19].

\section{Outlook}

Our research has shared up-to-date information and assessments of digitalization in Africa. It has provided an overview of the status quo, pointed out persisting inequalities (such as the gender digital divide), reflected on power relations and the role of different stakeholders in African digitalization processes, and laid out ethical concerns and considerations. Bringing together these various aspects of digitalization in Africa, it can be summed up that there are severe (structural) problems but also new opportunities for a more inclusive phase of digitalization in Africa. The future of digitalization in Africa has to deal with the enormous influence of foreign tech giants and the dangers of cultural and technological imperialism. The next phase of digitalization in Africa must also address the lack of responsible leadership and abusive practices of many African governments vis à vis their citizens. Since structures of inequality and unequal power relations inform digitalization processes, digitalization in Africa must rethink more fundamentally the premises that digitalization builds on. There are then opportunities for the inclusion of women and indigenous populations, democratization, economic development, and even digitalization being driven out of Africa. Ethical principles (virtue ethics) and the idea of sustainable development should be at the core of digitalization strategies in Africa to prevent further injustices to the African people.

The challenges that remain include inadequate infrastructure, the fact that most ICT systems are imported and controlled by foreign countries such as China and the USA, that there is limited research and innovation, and that the national budgets for digitalization are too low [3]. Moreover, costs for data and information access are too high and remains a barrier for many to take part in the digital evolution of Africa [6]. African governments have to step up for affordable internet (by tapping universal services funds) and show leadership [6, 3]. As long as African governments continue to see digitalization either as a peripheral issue or as a threat to stability, Africa will continue to lag behind [6]. While digitalization in the Global North has accelerated economic growth and prosperity, this is not the case in Africa. Government shutdowns cause enormous economic losses, but of course curtail political freedoms and prevent human and societal development as well [6].

Despite these challenges, hopes are high that the African people can benefit from the introduction of new technologies in terms of transparency, better tax collection, good governance, and digital/social movements; democratization is needed in Africa and ICT may assist in the struggle for human and people's rights protection [2]. There is even hope for a future digitalization "out of Africa"; Grant and Rademacher argue that the digital revolution is so successful because it is based on African values such as sharing and community orientation (see Ubuntu philosophy). Digital innovations are based on storytelling (Instagram and Snapchat) and flexibility and agility (Design thinking). There is then much potential for a digitalization "out of Africa" with African start-ups offering new ICT products for the global market [21]. Moreover, female African entrepreneurs invest in the promotion of women and women's tech skills by mentoring and developing inclusive business models [9]. There is then hope that more women will be more involved in shaping Africa's digital evolvement in the future.

On the other hand, cultural practices and structures of exclusion/oppression (such as patriarchy) are easily transported into the online world and digital work environments. If we want an inclusive digital society, we need to rethink these cultural norms, particularly gender roles, that reinforce men's dominance in offline and the online realms $[9,1]$. Similarly, power relations transported into technologies and the digital world (materializing in hegemonic communication practices and the 
dominance of the written (English) language) prevent the inclusion of African indigenous populations. The solution for an inclusive digital society in Africa must then be an "Africanization of ICT," which means taking into account end users' ways of life [10]. Finally, the reality of most African people remains that they have no access to ICT.

\section{Conclusion}

In light of the aforementioned challenges and opportunities, ethicists (in collaboration with actors in technology design and development work) face a series of questions for their research: what does an inclusive and just digital society look like? How can we build an inclusive and just digital society? What are ethical criteria for the development and implementation of new ICT products? What are intercultural approaches to technology development and innovation? Philosophers have begun engaging with these questions [14, 19, 2]. Virtue ethics is considered one key approach to forming a better information society [14]. Codes of ethics and responsibilities are needed when developing ICT; stakeholders in Africa's digitalization must take into account the long-term impact of digitalization and principles of sustainability [2]. Research on digitalization in Africa needs an ethical perspective. It should not be left to computer and information scientists but really be an interdisciplinary and intercultural endeavor, combining perspectives from sciences, and philosophy.

\section{References}

[1] Wakunuma, K. (2018) "Critical Questions at the Intersection of Digitalization, Development, and Justice." Presentation at the conference Digitalization in Africa: Interdisciplinary Perspectives on Technology, Development, and Justice on September 26 and 27, 2018 in Tübingen, Germany.

[2] Kelbessa, W. (2018) "Digitalization in Africa Opportunities and Challenges for Human Rights and Development." Presentation at the conference Digitalization in Africa: Interdisciplinary Perspectives on Technology, Development, and Justice on September 26 and 27, 2018 in Tübingen, Germany.

[3] Kwanya, T. (2018) "Digitalisation in Kenya: Status, Concerns and Opportunities." Presentation at the conference Digitalization in Africa: Interdisciplinary Perspectives on Technology, Development, and Justice on September 26 and 27, 2018 in Tübingen, Germany.

[4] Kiiza, A. (2018) "A Trojan Horse? E-Commerce and Its Potential Risks for Africa." Presentation at the conference Digitalization in Africa: Interdisciplinary Perspectives on Technology, Development, and Justice on September 26 and 27, 2018 in Tübingen, Germany.
[5] Pfeffer, K. and Verrest, H (2018) "Beyond the Boundaries: Addressing Social and Spatial Inequality with Digitally Based Mobility? The Case of Cape Town, South Africa" Presentation at the conference Digitalization in Africa: Interdisciplinary Perspectives on Technology, Development, and Justice on September 26 and 27, 2018 in Tübingen, Germany.

[6] Majama, K. (2018) "Exploring Africa's Digitalisation Agenda in the Context of Promoting Civil Liberties." Presentation at the conference Digitalization in Africa: Interdisciplinary Perspectives on Technology, Development, and Justice on September 26 and 27, 2018 in Tübingen, Germany.

[7] Kemp, S. (2018) "Digital in 2018: Essential Insights into Internet, Social Media, Mobile, and E-commerce Use Around the World.", We Are Social and Hootsuite; https://wearesocial.com/blog/2018 /01/global-digitalreport-2018 (Access Date: 13 October, 2018).

[8] Sègla, D. A. (2018) “Alternative Mobile Telephone Concepts and Web Information Infrastructure and Digital Tools by Illiterate Yoruba Peoples in Benin Republic." Presentation at the conference Digitalization in Africa: Interdisciplinary Perspectives on Technology, Development, and Justice on September 26 and 27, 2018 in Tübingen, Germany.

[9] Toffa, F. (2018) "Building a Digitally Skilled Generation for Sustainable, Impactful Development in Africa." Presentation at the conference Digitalization in Africa: Interdisciplinary Perspectives on Technology, Development, and Justice on September 26 and 27, 2018 in Tübingen, Germany.

[10] van Dijk, J.A. (2006) "Digital Divide Research, Achievements and Shortcomings", Poetics, Vol. 34 45, pp. 221-235.

[11] Fritzsche, K. (2018) "Concepts of Development and Justice Behind Tunisia's Digital Strategy." Presentation at the conference Digitalization in Africa: Interdisciplinary Perspectives on Technology, Development, and Justice on September 26 and 27, 2018 in Tübingen, Germany.

[12] Busch, U. (2018) "Building a Digital Business in Ghana - the Challenges to Overcome, the Opportunities Beyond." Presentation at the conference Digitalization in Africa: Interdisciplinary Perspectives on Technology, Development, and Justice on September 26 and 27, 2018 in Tübingen, Germany.

[13] Dark, S. (2018) "Strict New Internet Laws in Tanzania are Driving Bloggers and Content Creators Offline." The Verge; https://www.theverge.com/20 18 /7/6/17536686/tanzania-internet-laws-censorship-ugandasocial-media-tax (Access Date: 8, December 2018).

[14] Ess, C. (2018) "Culture, Digitalization, and the Digital Divide: Existential and Virtue Ethics Approaches. A (long) view from the (far) North." Presentation at the conference Digitalization in Africa: Interdisciplinary Perspectives on Technology, Development, and Justice on September 26 and 27, 2018 in Tübingen, Germany. 
[15] Simon, J. (2016) "Values in Design." In: Heesen, Jessica (ed). 2016. Handbuch Medien und Informationsethik. J.B. Metzler, Stuttgart, pp. 357-364.

[16] Global Voices (2017) "Free Basics in Real Life: Six case studies on Facebook's internet "On Ramp" initiative from Africa, Asia and Latin America"; https://advox.globalvoices.org/wp-content/uploads /2017/08/FreeBasicsinRealLife_FINALJuly27.pdf (Access Date: 7 November, 2018).

[17] Ess, C. (2009) Digital Media Ethics. Cambridge and Malden, MA: Polity Press.

[18] Tavani, H. T. (2007) Ethics and Technology: Ethical Issues in an Age of Information and Communication Technology. Hoboken, NJ: Wiley.

[19] Heesen, J. (2018) "Ethical Questions about Digitalisation in Africa." Presentation at the conference Digitalization in Africa: Interdisciplinary Perspectives on Technology, Development, and Justice on September 26 and 27, 2018 in Tübingen, Germany.

[20] Heeks, R. (2008) "ICT4D 2.0: The Next Phase of Applying ICT for International Development." Computer 41(6), pp. 26-33.

[21] Rademacher, U., and Grant, T. (2018) "Out of Africa - A New Perspective on Digitalisation in Africa." Presentation at the conference Digitalization in Africa: Interdisciplinary Perspectives on Technology, Development, and Justice on September 26 and 27, 2018 in Tübingen, Germany. 